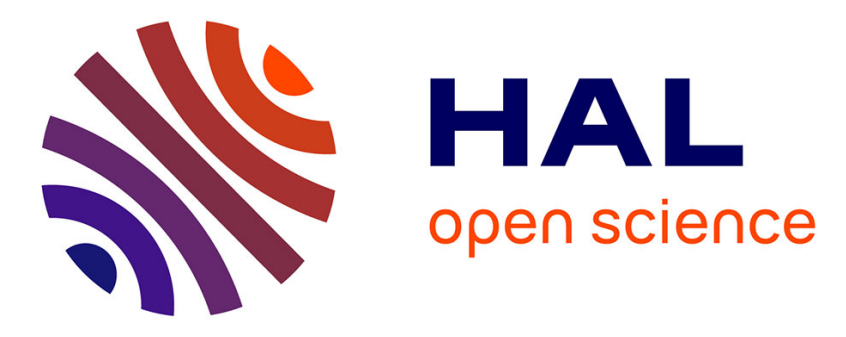

\title{
Low-lying Yrast states in 218Th
}

A. Chevallier, Jacques Chevallier, S. Khazrouni, L. Kraus, I. Linck, D.C. Radford, N. Schulz

\section{To cite this version:}

A. Chevallier, Jacques Chevallier, S. Khazrouni, L. Kraus, I. Linck, et al.. Low-lying Yrast states in 218Th. Journal de Physique, 1982, 43 (11), pp.1597-1598. 10.1051/jphys:0198200430110159700 . jpa-00209541

\section{HAL Id: jpa-00209541 https://hal.science/jpa-00209541}

Submitted on 1 Jan 1982

HAL is a multi-disciplinary open access archive for the deposit and dissemination of scientific research documents, whether they are published or not. The documents may come from teaching and research institutions in France or abroad, or from public or private research centers.
L'archive ouverte pluridisciplinaire HAL, est destinée au dépôt et à la diffusion de documents scientifiques de niveau recherche, publiés ou non, émanant des établissements d'enseignement et de recherche français ou étrangers, des laboratoires publics ou privés. 
Classification

Physics Abstracts

$23.20 \mathrm{~L}-27.80$

\title{
Low-lying Yrast states in ${ }^{218}$ Th
}

\author{
A. Chevallier, J. Chevallier, S. Khazrouni, L. Kraus, I. Linck, D. C. Radford and N. Schulz \\ Centre de Recherches Nucléaires et Université Louis-Pasteur, 67037 Strasbourg Cedex, France
}

(Reçu le 25 mai 1982, révisé le 17 juillet, accepté le 26 juillet 1982)

\begin{abstract}
Résumé. - Dans la réaction ${ }^{206} \mathrm{~Pb}\left({ }^{16} \mathrm{O}, 4 \mathrm{n}\right){ }^{218} \mathrm{Th}$, des rayonnements $\gamma$ ont été observés en coïncidence avec les particules $\alpha$ de la décroissance de l'état fondamental. Une proposition de schéma de décroissance du ${ }^{218} \mathrm{Th}$ est faite.
\end{abstract}

Abstract. - Gamma-rays in coincidence with the $\alpha$-particles from the decay of the ground-state of ${ }^{218} \mathrm{Th}$ have been observed in the ${ }^{206} \mathrm{~Pb}\left({ }^{16} \mathrm{O}, 4 \mathrm{n}\right)$ reaction. A tentative decay scheme of ${ }^{218} \mathrm{Th}$ is proposed.

Nuclei in the vicinity of the doubly closed ${ }^{208} \mathrm{~Pb}$ core $(N=126, Z=82)$ have attracted a great deal of experimental and theoretical work. For nuclei with both proton and neutron particles outside this core, there is however a lack of experimental information on Yrast states. This is due on one hand to the difficulty of finding suitable target-ion beam combinations. On the other hand, for elements above radium isotopes $(Z=88)$, the magnitude of the cross-section for transfer reactions is comparable to that of compound nuclear formation, where the fission channel prevails over the fusion-evaporation channel. In that case the background problem encountered in $\gamma$-ray in-beam measurements can be overcome for $N=128$, 129 nuclei by making use of the short lifetime of the $\alpha$ decaying ground-states. This has been done for ${ }^{218} \mathrm{Th}$ by selecting the $\gamma$-rays in coincidence with the $\alpha$ particles from the decay of the ground state, which has a half-life $T_{1 / 2} \simeq 0.11 \mu \mathrm{s}[1,2]$.

Excited states in ${ }^{218} \mathrm{Th}$ were produced via the ${ }^{206} \mathrm{~Pb}\left({ }^{16} \mathrm{O}, 4 \mathrm{n}\right)$ reaction with an incident beam of $92 \mathrm{MeV}$ provided by the Strasbourg M.P. tandem accelerator. The ${ }^{16} \mathrm{O}$ beam was pulsed with a repetition time of $400 \mathrm{~ns}$ and the resulting beam bursts had a time spread of about $1 \mathrm{~ns}$. The time reference for the beam bursts was provided by a chevron channel plate array detecting secondary electrons emitted from a carbon foil placed $1 \mathrm{~m}$ in front of the target [3]. A $1.8 \mathrm{mg} / \mathrm{cm}^{2}$ self-supporting ${ }^{206} \mathrm{~Pb}$ target was set at an angle of $65^{\circ}$ with respect to the beam axis. In such a way, the effective thickness of the target was twice the range for recoiling Th ions and part of the

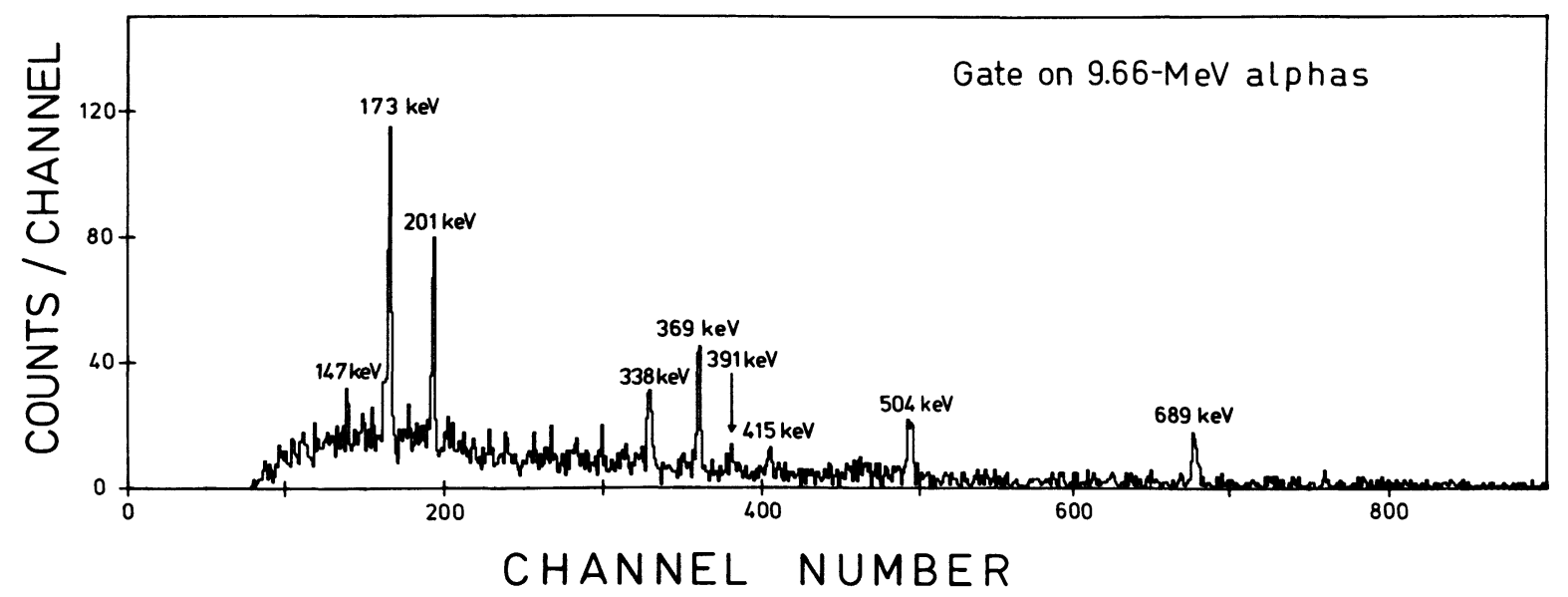

Fig. 1. - Gamma-ray spectrum in coincidence with delayed $\alpha$-particles from the decay of the ${ }^{218}$ Th ground-state. 
$\alpha$-decaying nuclei produced by the reaction were stopped in the target. The $\alpha$-particles were detected with a Si surface-barrier detector of $300 \mathrm{~mm}^{2}$ area and $200 \mu \mathrm{m}$ thickness mounted at a distance of $35 \mathrm{~mm}$ from the target and an angle of $140^{\circ}$. Gamma-rays were detected in a $9 \mathrm{~cm}^{3}$ planar $\mathrm{Ge}(\mathrm{Li})$ detector, having good timing properties, set at $90^{\circ}$.

A singles $\alpha$-particle spectrum was recorded in order to observe possible delayed $\alpha$-particles arising from excited states in ${ }^{218} \mathrm{Th}$. No such particles with a mean-life greater than $10 \mathrm{~ns}$ and an intensity larger than $3 \%$ of the ground-state intensity have been observed. This measurement also yields a value of $T_{1 / 2}=125 \pm 5 \mathrm{~ns}$ for the half-life of the groundstate of ${ }^{218} \mathrm{Th}$, in agreement with one of the previously reported values [1].

Table I. - Results of the $\alpha-\gamma$ coincidence measurement

$\begin{array}{cccc}E_{\gamma}(\mathrm{keV})\left({ }^{a}\right) & I_{\gamma}\left({ }^{b}\right) & E_{\gamma}\left({ }^{a}\right) & I_{\gamma}\left({ }^{b}\right) \\ - & - & - & - \\ 146.9 \pm 1.0 & 4 \pm 2 & 390.5 \pm 1.0 & 19 \pm 6 \\ 173.3 & 44 \pm 4 & 414.5 \pm 1.0 & 25 \pm 8 \\ 201.2 & 37 \pm 4 & 504.4 & 98 \pm 15 \\ 338.4 & 57 \pm 8 & 688.8 & 100 \pm 17 \\ 369.2 & 80 \pm 9 & & \end{array}$

( ${ }^{(9)}$ Gamma-ray energies are accurate to $\pm 0.6 \mathrm{keV}$, unless otherwise indicated.

(b) Gamma-ray intensities are normalized to the $688.8 \mathrm{keV}$ yield.

Gamma-rays in coincidence with delayed alphaparticles of $9.66 \mathrm{MeV}$ emitted by the ${ }^{218} \mathrm{Th}$ groundstate were recorded for 30 hours. The resulting spectrum is displayed in figure 1 and the $\gamma$-ray intensities are listed in table I. The strongest $\gamma$-transitions observed in ${ }^{218} \mathrm{Th}$ are prompt transitions $\left(T_{1 / 2}<4 \mathrm{~ns}\right)$ as may be seen in figure 2 which shows the added time distributions of two of the stronger $\gamma$-rays with respect to the beam burst. The absence of a measurable lifetime in ${ }^{218} \mathrm{Th}$ explains why, in contrast to other even- $A N=128$ isotones [4-6], no long-range $\alpha$-particles arising from excited states could be observed.

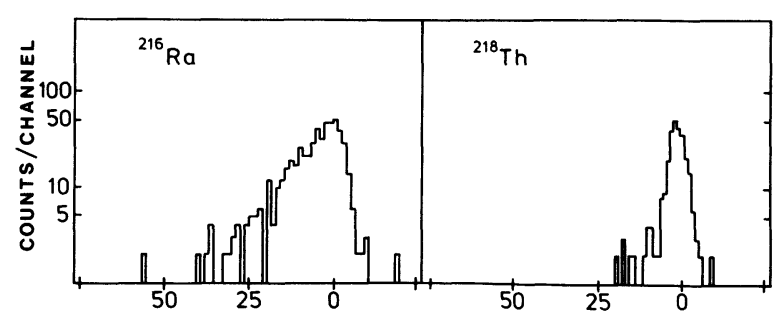

Fig. 2. - Added time distributions with respect to the beam burst for the 338- and $369-\mathrm{keV} \gamma$-transitions in ${ }^{218} \mathrm{Th}$ (right part). The left part of the figure shows the added time spectra for the 309-, 315- and 345-keV $\gamma$-transitions in ${ }^{216} \mathrm{Ra}$ governed by a 7 ns half-life [7], obtained by gating on the 9.35 $\mathrm{MeV} \alpha$-group from the decay of the ${ }^{216} \mathrm{Ra}$ groundstate.

The production of ${ }^{218} \mathrm{Th}$ in the ${ }^{206} \mathrm{~Pb}+{ }^{16} \mathrm{O}$ reaction represents only a very small part of the total cross-section, less than $0.3 \%$ according to both the ${ }^{206} \mathrm{~Pb}\left({ }^{16} \mathrm{O}, 4 \mathrm{n}\right)$ and fission cross-section measurements $[1,9]$. Therefore, in the present experiment no peaks attributed to ${ }^{218} \mathrm{Th} \gamma$-transitions could be observed in singles $\gamma$-spectra and this hampered further measurements such as $\gamma$-ray angular distributions. However, according to the general trend observed in the excitation energies of the Yrast states in the even- $A N=128$ isotones (see Fig. 3) and taking into account the measured $\gamma$-ray intensities, a tentative level scheme of ${ }^{218} \mathrm{Th}$ can be proposed, consisting of a cascade of the 369,504 and $689 \mathrm{keV} \gamma$-rays, probably preceded by the $201 \mathrm{keV} \gamma$-ray.

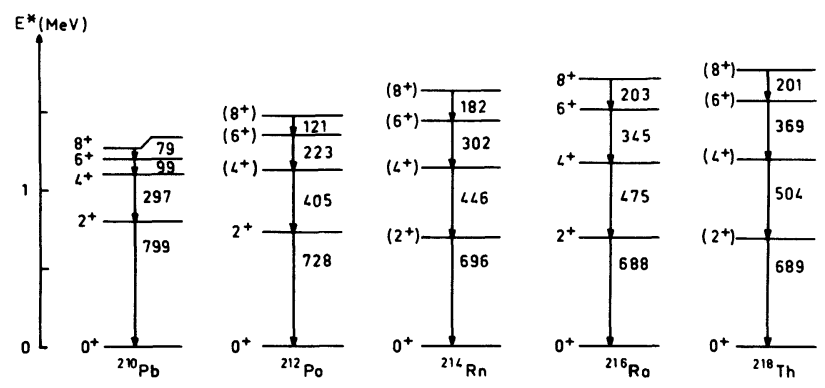

Fig. 3. - Excitation energies of the first $2^{+}, 4^{+}, 6^{+}$and $8^{+}$states in the $N=128$ isotones: ${ }^{210} \mathrm{~Pb},{ }^{212} \mathrm{Po}[8],{ }^{214} \mathrm{Rn}$ [6], ${ }^{216} \mathrm{Ra}[4,7]$ and the proposed level scheme for ${ }^{218} \mathrm{Th}$.

\section{References}

[1] Haüsser, O., Witthuhn, W., AleXander, T. K., MCDonald, A. B., Milton, J. C. D. and Olin, A., Phys. Rev. Lett. 31 (1973) 323.

[2] Nomura, T., Hiruta, K., InAmura, T. and Odera, M., Nucl. Phys. A 217 (1973) 253.

[3] Chevallier, A., Chevallier, J., Coffin, J. P., EngelStein, P., HaAs, B. and SchUlz, N., Nucl. Instrum. Methods 171 (1979) 193.

[4] Nomura, T., Hiruta, K., Yoschie, M., Ikezoe, H., Fukuda, T. and HaShimoto, O., Phys. Lett. 58B (1975) 273.
[5] Lieder, R. M., Didelez, J. P., Beuscher, H., HaENNi, D. R., Müller-Veggian, M., NesKakis, A. and MAYER-BÖRICKE, C., Phys. Rev. Lett. 41 (1978) 742.

[6] Gono, Y., Hiruta, K., Nomura, T., Ishihara, M., Utsunomiya, H., Sugitate, T. and Ieki, K., $J$. Phys. Soc. Japan 50 (1981) 377.

[7] Khazrouni, S., Thesis 3e cycle (1982), Université LouisPasteur, Strasbourg.

[8] Bohn, H., Endres, E., Faestermann, T. and Kienle, P., Z. Phys. A 302 (1981) 51.

[9] Sikkeland, T., Phys. Rev. 135 (1964) B 669. 